\title{
DESENVOLVIMENTO DE UM PROTÓTIPO HUMANOIDE POR MEIO DE IMPRESSÕES 3D PARA DESENVOLVIMENTO DE NOVAS TECNOLOGIAS
}

${ }^{1}$ Matheus Henrique Nunes França; ${ }^{2}$ Fredson da Silva Oliveira; Oberdan Rocha Pinheiro ${ }^{3}$

${ }^{1}$ Matheus Henrique Nunes França; Salvador/Bahia; br matheus@hotmail.com

\section{ÁREA 1 | Wyden; Salvador/Bahia}

Resumo: A robótica tem sido impulsionada pelas possibilidades da utilização de robôs para auxiliar o ser humano em diversas tarefas, principalmente em ambientes hostis para o ser humano. Para conseguir lidar com os diferentes tipos de ambientes, é de grande importância que os robôs sejam adaptáveis ao meio em que estão inseridos. Nesse sentido, o objetivo geral deste trabalho é desenvolver um protótipo de um robô humanoide por meio de impressão 3D que seja o mais próximo possível do ser humano. O protótipo será utilizado como berço de testes e assim promoverá o avanço nas técnicas mais diversas em robótica e inteligência artificial.

Palavras-Chave: Humanoide; Impressão 3D; Robótica.

\section{DEVELOPING A HUMANOID PROTOTYPE THROUGH 3D PRINTING FOR DEVELOPING NEW TECHNOLOGIES}

\begin{abstract}
Robotics has been driven by the possibilities of using robots to assist humans in various tasks, especially in environments hostile to humans. In order to cope with different types of environments, it is of great importance that robots are adaptable to the environment in which they operate. In this sense, the general objective of this work is to develop a prototype of a humanoid robot through $3 D$ printing that is as close as possible to the human being. The prototype will be used as the cradle of tests and thus will advance the most diverse techniques in robotics and artificial intelligence.
\end{abstract}

Keywords: Humanoid; 3D printing; Robotics. 


\section{INTRODUÇÃO}

O crescente interesse em robôs humanoides estimulou um aumento substancial em seu desenvolvimento ao longo da última década. Os humanoides existentes podem ser categorizados como: humanoides com rodas, humanoides com pernas e semelhantes aos humanos [1]. Este projeto de pesquisa propõe um protótipo de humanoide de código aberto, impresso em 3D. Em particular, o uso de tecnologias de impressão 3D e prototipagem rápida é um aspecto central deste projeto e torna fácil e rápido não apenas reproduzir a plataforma, mas também explorar seu uso no campo da ciência e educação. O projeto foi inicialmente planejado com objetivo científico, visando ser uma plataforma experimental, abrindo possibilidade de estudar sistematicamente o papel da morfologia no controle sensório-motor, na interação homem-robô e no desenvolvimento cognitivo.

\section{METODOLOGIA}

A concepção do robô humanoide leva em consideração todas as características antropomórficas humanas. Nesse sentido, ele foi construído com atuação híbrida, projetada para auxiliar os motores com o objetivo de melhorar a eficiência energética ao movimentar suas juntas. O design foi desenvolvido com auxílio do software Fusion 360 , já as peças foram fabricadas com auxílio de uma impressora 3D. Foram utilizados 17 servos motores LX-16A da LOBOT, um Kinect Sensor Xbox 360, uma raspberry pi 3, 7 giroscópios mpu6050 e 8 sensores de força sparkfun 5", sendo esses os elementos que compõe o protótipo. A seguir descrição das etapas para construção do protótipo.

\subsection{Atuação passiva e ativa}

Um dos grandes desafios do projeto é desenvolver um caminhar semelhante ao humano e robustez quando na presença de distúrbios, tais como variações do terreno (i.e. [2]). Os problemas principais associados com a análise e o controle de robôs bípedes são as mudanças devido principalmente ao impacto da perna com o solo. Por isso foi necessária uma estrutura resistente e que minimize os esforços dos motores. Foram analisadas duas categorias de robôs bípedes: 1) atuação ativa: Robôs bípedes que possuem pés e atuadores em algumas das juntas. A atuação é realizada de tal forma a aproveitar as características naturais do caminhar; 2) atuação passiva: Robôs bípedes puramente passivos, sem pés e sem controle de torque ou de posição.

\subsection{Dimensionamento da estrutura e servo motores}

\subsubsection{Estrutura:}

A estrutura robótica, assim como a humana, tem atuadores que thes dão os diversos graus de liberdade (i.e. [3]) necessários para o movimento natural. Para cada junta foi necessário um estudo de movimento, para saber quantos motores seriam inseridos. Para cada GDL é necessário um atuador, sendo assim o dimensionamento 
da estrutura depende de quantos motores serão inseridos, porém, para determinar os motores é necessário ter parâmetros como peso e tamanho da estrutura. Conclui-se então que o dimensionamento da estrutura e dos atuadores estão diretamente relacionados, logo optamos por fazer uma restrição na qual possa se tomar as decisões. Foi feita a delimitação da estrutura, optou-se por fazer uma estrutura pequena, porém, que não perdesse as características do ser humano, foi escolhida a dimensão máxima de 1 metro. Após a escolha, foi preciso apenas fazer uma escala com o corpo humano e então são obtidas as dimensões necessárias para iniciar o projeto. Com as delimitações feitas na estrutura, pode-se partir para o detalhamento do motor.

\subsubsection{Servo motor:}

O servo (atuador) escolhido para o projeto, trabalha com servomecanismo que usa o feedback de posição para controlar a velocidade e a posição final do motor. Internamente, um servo combina um motor com um circuito de realimentação, um controlador e outros circuitos complementares. Ele usa um codificador ou sensor de velocidade (encoder) que tem a função de fornecer o feedback de velocidade e posição. O servo escolhido foi o LX16-A da lobot LewanSoul, ele tem como parâmetros os feedbacks de velocidade e posição já citados e também de temperatura e tensão para um maior controle. Assim como tem um grande torque e uma pequena dimensão.

\subsection{Desenho assistido por computador (CAD) e análises estruturais}

Foi necessário um estudo completo sobre o corpo humano para assim, com o dimensionamento da estrutura e o motor escolhido, ser iniciada a parte do desenho técnico do projeto. O desenho foi todo feito no software Fusion 360, o modelo serviu para a produção na impressora $3 d$ e antes disso para os testes de liberdade de movimentação que o corpo teria, corrigindo eventuais erros. Depois do desenho ser feito ele é processado pelo programa da impressora 3D, que neste caso será utilizado - Simplify 3D, para gerar o código de máquina (código g) e assim fazer a peça propriamente dita.

\subsubsection{Pé}

O projeto foi iniciado pela simplificação dos dedos do pé pela sua complexidade, porém não comprometendo a marcha, assim sendo o pé vai necessitar de apenas um eixo de rotação para os dedos. Os pés (Figura 1) também irão comportar um conjunto de sensores de força para a análise de impacto do pé com o solo e um sensor (mpu6050) que contém giroscópio, acelerômetro e captura de temperatura. Para que não deslize em superfícies lisas, foram utilizados solados de borracha. Fez-se necessário inserir 4 cavidades para o acoplamento de sensores de força, e um fim de curso mecânico no dedo para que ele não ultrapasse a hiperextensão de 45․

Figura 1. a) vista do topo do pé com silicone (mostrando fim de curso mecânico). b) vista inferior do pé sem o silicone (mostrando as cavidades para os sensores). 


\section{\begin{tabular}{l|l} 
CIRCULAR ECONOMY & ECONOMIA CIRCULAR
\end{tabular}}
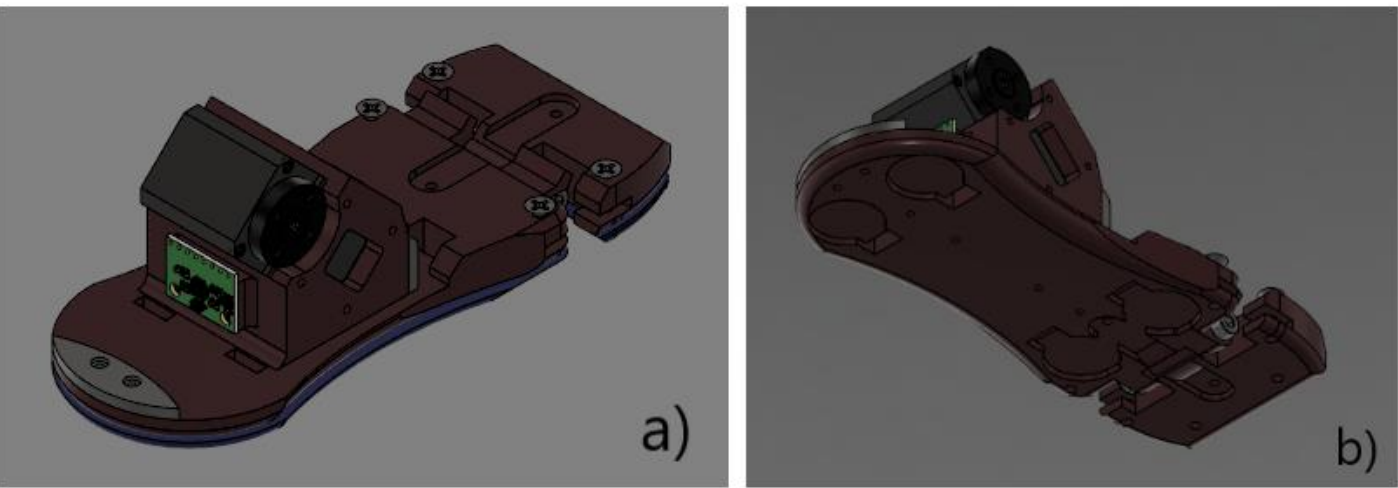

\subsubsection{Tornozelo}

Para comportar os três atuadores de movimentos do pé, de forma a maximizar os espaços, um atuador está acoplado na parte do pé, um no tornozelo e o outro logo em cima, na parte da canela. Pode-se ver a disposição do tornozelo com o pé na Figura 2.

Figura 2. a) tornozelo vista frontal. b) tornozelo conectado ao pé.
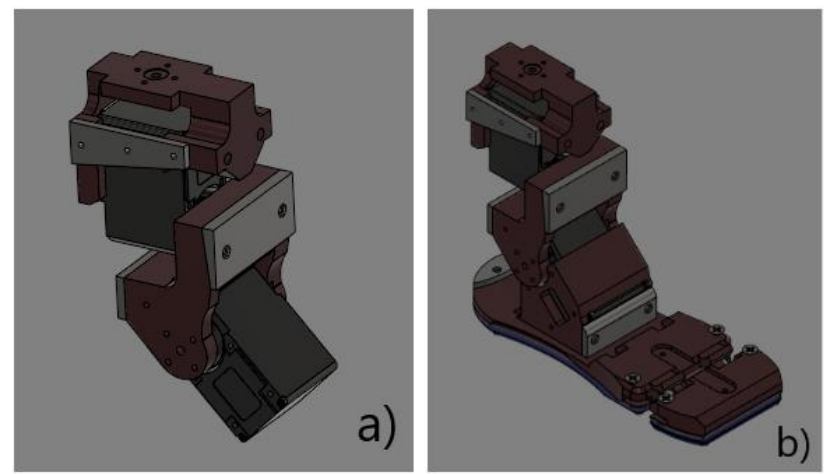

\subsubsection{Canela}

A canela (Figura 3) irá comportar tanto o motor do movimento do pé quanto o do joelho. Isso fará com que ocorra a otimização do espaço no humanoide. Também foi colocado mais um giroscópio neste membro para a análise dos movimentos e inserimos também tubos para enrijecer a estrutura.

Figura 3. a) Vista frontal da canela já acoplado ao joelho. b) Vista posterior da canela.
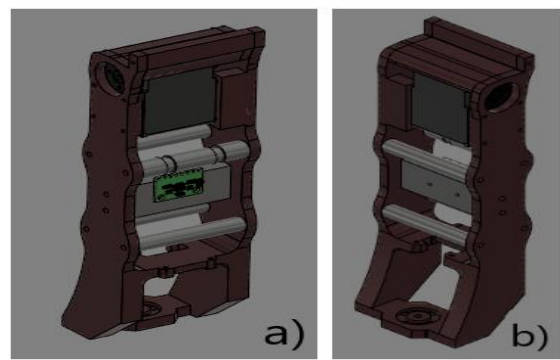


\subsubsection{Joelho}

No joelho é necessário apenas um grau de liberdade, portanto o sistema foi mais simples do que no tornozelo. Como já citado o motor é alojado na canela. Sua transmissão é feita diretamente no eixo do motor o que mantém uma relação de 1:1 para não mudar o torque nem a velocidade do mesmo. Apesar de sua simplicidade, o joelho é uma articulação muito demandada pela estrutura do robô (i.e. [4]). A estrutura assim como o dedo do pé, também comporta um fim de curso mecânico que limita a estrutura para só haver o seu movimento de flexão, deixando de lado uma hiperextensão desnecessária.

\subsubsection{Coxa}

A coxa (Figura 4) foi dividida em duas partes, a primeira parte acoplada ao joelho comporta o sensor giroscópio, tubos de fortificações estruturais e o motor de rotação lateral e medial do quadril ou da coxa. A segunda parte comporta o ligamento do quadril que faz os movimentos de abdução e hiperabdução.

Figura 4. Coxa com todas as peças montadas no software fusion 360.

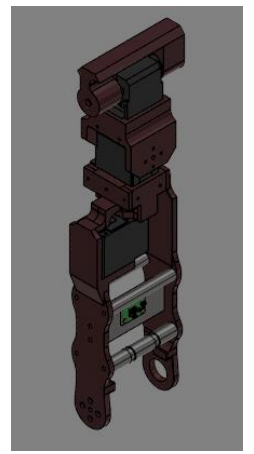

\subsubsection{Quadril}

O quadril (Figura 5) necessita comportar 3 graus de liberdade para a perna e 1 grau de liberdade para o tronco.

Figura 5. a) Quadril na vista frontal. b) Quadril na vista posterior com o servo aparente.
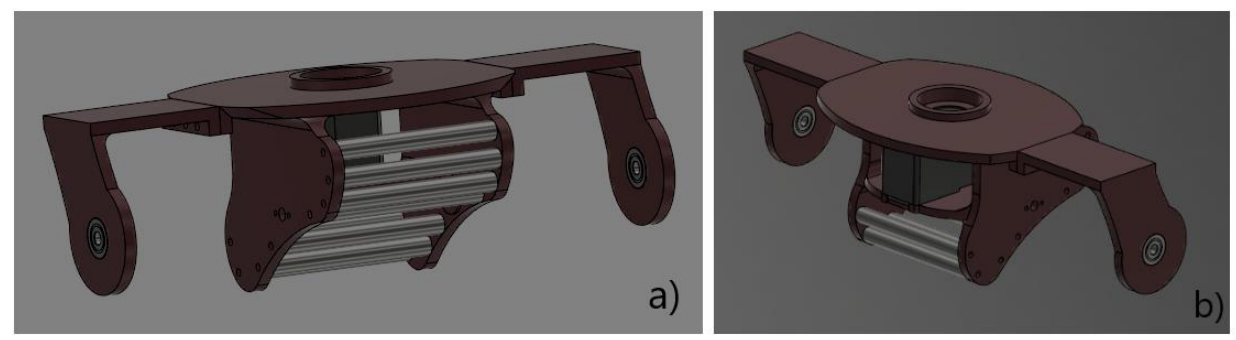

Os eixos dos motores são conectados à estrutura em cascata, que apesar de não ser antropomorficamente correto, não afetou o seu movimento final esperado. Como essa é uma peça grande na estrutura do robô, foi necessário dividir em três 
partes. A primeira comporta o motor de rotação do tronco, e as outras duas fazem a ligação da parte central com a articulação da coxa. Também foram colocados cilindros para aumentar a sua resistência e um rolamento para ajudar na movimentação do tronco.

\subsubsection{Tronco}

O tronco (Figura 6) vai conter 3 graus de liberdade, e assim como as outras juntas da estrutura, vai ser conectada em cascata. O movimento rotacional como já mencionado ficará inserido no quadril. O tronco vai acomodar a parte central da eletrônica. Terá um giroscópio, a placa buslinker para o servo, o raspberry pi 3 para a parte de controle, além de conter caixas de som, uma tela lcd e um Kinect no seu topo.

Figura 6. a) Tronco com tampa que contém o lcd. b) Tronco com parte da eletrônica visível.
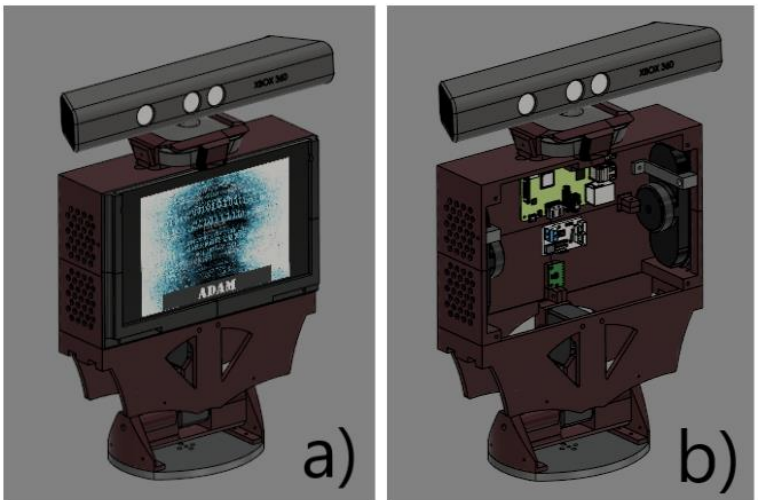

\subsection{Produção da estrutura}

Foi concebida uma solução bastante satisfatória depois da realização dos desenhos do humanoide, acomodando um total de 19 graus de liberdade (sendo 2 deles puramente passivos, Tabela 1) e com as dimensões de um ser humano com a altura aproximada de 1 metro. Esta solução satisfaz todas as exigências impostas no início deste trabalho relativas às medidas e movimentação.

Tabela 1. Distribuição dos GdL's (Graus de liberdade) do robô humanoide Adam.

\begin{tabular}{|c|c|}
\hline Articulação & Número Gdl's \\
\hline Pé & $1(x 2)$ \\
\hline Tornozelo & $3(x 2)$ \\
\hline Joelho & $1(x 2)$ \\
\hline Quadril & $3(x 2)$ \\
\hline Tronco & 3 \\
\hline Total & 19 \\
\hline
\end{tabular}




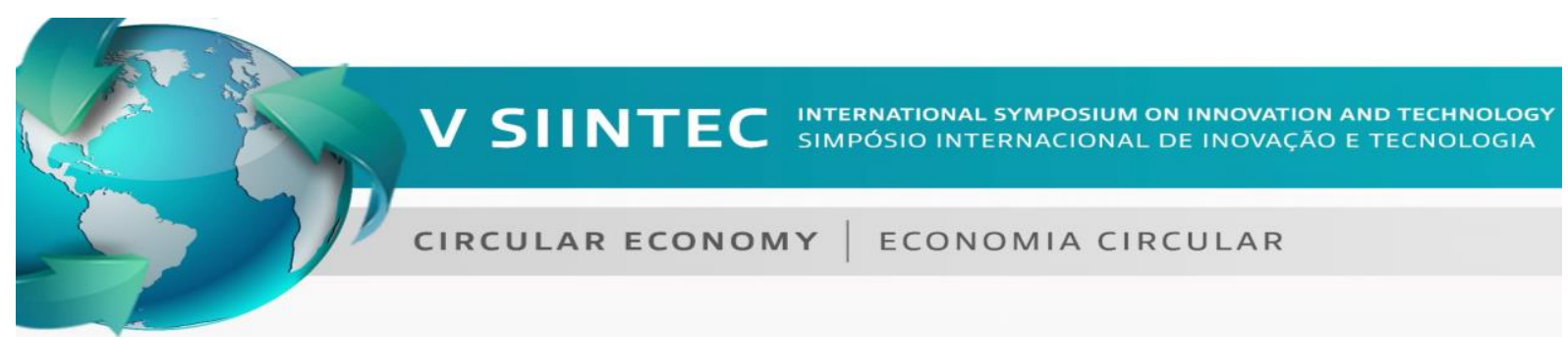

Para a construção da estrutura citada, foi utilizada a impressora 3d anet a8 por possuir um baixo custo de produção e uma ótima qualidade técnica. Nela utilizou-se do filamento petg xt que é um material de alta resistência mecânica, química e à altas temperaturas, dureza e odor neutro de processamento. O PETG é um copoliéster durável. O PET, pense no plástico de garrafas, e o G do glicol modificado para durabilidade extra. Começamos a impressão das peças pela parte do pé, que consiste em duas peças e as quatro peças que compõem o molde para o silicone, seguido por todas as outras partes que se constitui a perna direita e o quadril, para só então começar a perna esquerda e o tronco. Depois de finalizado a impressão $3 \mathrm{~d}$ e a montagem, partimos para a colocação dos atuadores passivos, que neste caso foram utilizados elásticos. Em seguida foram colocados os sensores e toda parte de eletrônica e só então foram instaladas as placas que cobrem toda a estrutura.

\section{RESULTADOS E DISCUSSÃO}

O projeto estrutural (Figura 7) foi desenvolvido em impressora $3 \mathrm{~d}$ com um material ecologicamente correto, sendo construído a princípio a parte do tronco e pernas do robô, para só então, em um trabalho futuro, serem construídos os membros superiores e a cabeça. Todos os movimentos atingiram as amplitudes requisitadas para a estrutura desejada. Assim como o tamanho desejado. Foi inserido assertivamente os atuadores passivos que ajudam os servos motores. Uma perda mecânica foi observada nas ligações que requerem muito dos atuadores, pelo fato da estrutura ser de copoliéster e não de um material mais resistente como um alumínio. Assim fica visível um desgaste muito mais rápido nos eixos de movimentação, causando uma defasagem nos ângulos de movimento.

Figura 7. a) Vista sem placas de proteção. b) Vista com placas de proteção. c) Estrutura já maquinada e com atuador passivo.
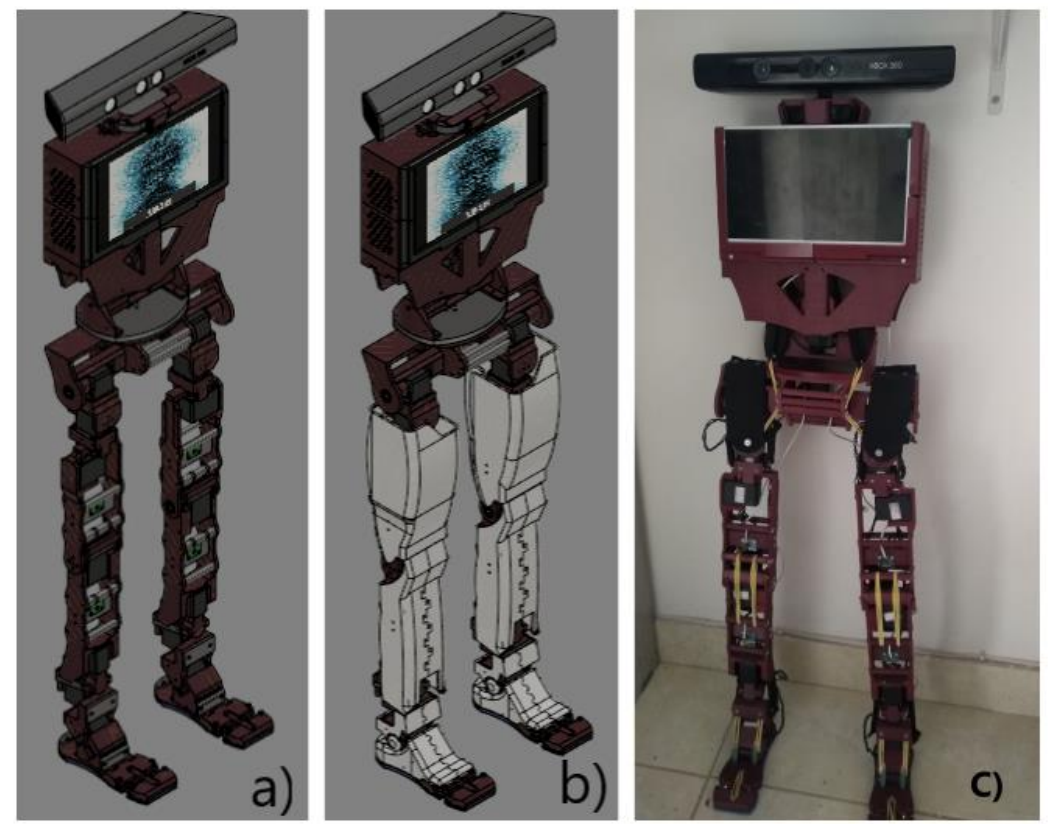


\section{CONCLUSÃO}

A robótica tem sido impulsionada pelas possibilidades de utilização de robôs para auxiliar o ser humano em diversas tarefas. Para conseguir lidar com os diferentes tipos de ambientes, é de grande importância que os robôs consigam desenvolver estratégias de locomoção que sejam adaptáveis com o meio em que estão inseridos. Nesse sentido, o protótipo humanoide, desenvolvido neste trabalho de pesquisa, teve como um dos intuitos gerar um berço de testes em que pesquisadores na área da robótica possam desenvolver seus estudos, trazendo assim uma possibilidade enriquecedora de compartilhamento de conhecimentos, e acelerando o desenvolvimento neste campo de pesquisa. Outra possibilidade do humanoide é a inserção em escolas com o intuito de aumentar o interesse dos estudantes nesta área. A princípio foi criada uma plataforma na qual se constitui de pernas, tronco e a parte de visão computacional com o Kinect. Todo o protótipo feito em impressora 3d utiliza tanto de atuação ativa (com motores) quanto de atuação passiva (elásticos) em suas articulações. Utilizamos também sensores para capturar o máximo de feedbacks do mundo exterior. Como trabalho futuro da pesquisa, sugere-se o desenvolvimento do controle de estabilidade e caminhada baseados em agentes inteligentes deliberativos utilizando técnicas avançadas de aprendizagem de máquina.

\section{REFERÊNCIAS}

${ }^{1}$ Bar-Cohen, Y.; Hanson, D.; Marom, A. The Coming Robot Revolution; Springer: Berlin, Germany; Heidelberg, Germany, 2009.

2SARIYILDIZ, Emre; TEMELTAS, Hakan Turkish Journal of Electrical Engineering \& Computer Sciences. 2017, Vol. 25 Issue 2, p1495-2. 16p.

${ }^{3}$ Lida, Fumiya; Minekawa, Yohei; Rummel, Jürgen e Seyfarth, André (2009). "Toward a human-like biped robot with compliant legs". Robotics and Autonomous Systems 57, pp139-144.

${ }^{4}$ Lahr, Derek F.; Yi, Hak; Hong, Dennis. Advanced Robotics. Jan2016, Vol. 30 Issue 2, p109-118. 10p. 